Results In a total of 24 providers courses during the 2008 and 2012, 529 doctors participated and among them 417 completed the course successfully. 43 faculty members also developed to run the course. Trained $87.5 \%$ doctors are using EMSB skills in burn management. About 38\% doctor felt that the course helped them to improve their confidence. Majority of doctors stated EMSB is essential for the Bangladeshi doctors to learn better management of burn. From qualitative study it was found that the courses maintaining same quality and standard as running anywhere in the world. However, it has recommended to train nurses and more doctors from periphery of the country.

Conclusions EMSB created a large doctors community who are effectively managing burn patients. It also create demand for learning burn management skill. EMSB training is required for medical doctors and nurses at the grass root level which could avert a number of deaths and also reduce the severity of the burn injuries.

\section{A SAFER CANDLE PROJECT SOUTH AFRICA}

PP Mtambeka, D Schulman, N du Toit, H. Rode, AB Van As. Childsafe South Africa, Red Cross War Memorial Children's Hospital

\subsection{6/injuryprev-2016-042156.802}

Background There are two main causes of shack fires in South Africa: Fallen candles and paraffin-related burns. These fires lead to devastating consequences and huge economic losses.

Aim/goal The goal of this project is to facilitate and promote safer use of candles in a glass jar, with the ultimate aim to prevent fires, burn injuries and deaths caused by fallen candles, targeting individuals and families who live in informal homes.

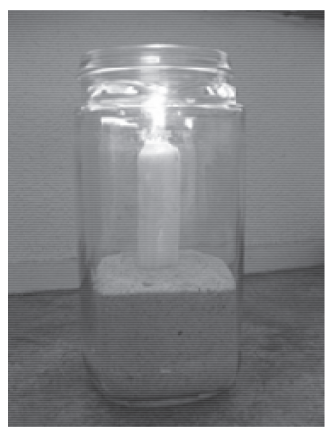

Material and methods Childsafe South Africa personnel conducted a number of trials to test the "Candle in a glass jar" concept. In 2006, the project was piloted in an informal area that exclusively uses candles as source of light. Further demonstration and educational sessions have taken place and over 100,000 jar units have been distributed to various communities to date.

Results The Safer Candle Project has become one of Childsafe's established out-reach programmes over 10 year period.It has been widely accepted and been approved by World Wide Fund for Nature SA (WWF) for Earth Hour and endorsed by various stakeholders and sponsors.

Significance The idea of candle in the glass jar is recommended as its very simple and preventative measure to reduce fires mainly caused by candles tipping. One of its advantages is that it places no financial burden on families, as there are virtually no costs involved.

\section{FIRE SAFETY PRACTICES IN INSTITUTIONAL, RESIDENTIAL AND HOME CARE IN FINLAND}

Markus Grönfors, Tarja Ojala, Nina Martikainen, Satu Pajala, Anne Lounamaa. National Institute for Health and Welfare, Finland

\subsection{6/injuryprev-2016-042156.803}

Background The rescue act 2011 in Finland stresses that the responsibility of fire safety is on building owners and service providers. The regulation is justifiable, because people in vulnerable positions, for example elderly and disabled, have an increased risk being fire victims.

The aim of this study was to investigate the implementation of rescue service act among service providers in residential, institutional and home care facilities and to monitor changes from 2013 to 2015.

Methods Online surveys on fire hazard assessment and risk management practices were done in 2013 and 2015. Respondents were managers of residential, institutional and home care facilities for the vulnerable people.

Information of the facilities was obtained from the nationwide Register of Institutions in Social Welfare and Health Care. The study sample was systematically selected (every other) and it consisted 1605 organisations.

Results In 2013 93\% of institutional and 95\% residential units had written guidelines to ensure fire safety. In 2015 the proportion has decreased to 84 in institutional and $88 \%$ in residential units. At home care written guidelines had less than $50 \%$. The accident prevention guidelines had increased in institutional units from $66 \%$ to $74 \%$ and in residential units from $66 \%$ to $77 \%$. At home care the guidelines had $50 \%$. Safety guidelines in general e.g. crime prevention has also decreased and was now less than 50\%, at home care only $22 \%$. Patient and residential safety guidelines were increased only at home care from $55 \%$ to $60 \%$.

Conclusions The organisations have increased their preparedness for fire risk with sprinklers. But at the same time they made less written guidelines to prevent to fire. Fire risk assessment and management practices have improved only in home care. In IR-units the situation seems to be weaker than in 2013. The situation is not acceptable and the reasons should be diagnosed.

\section{Preparedness and Resilience}

\section{Post Tue 2.21}

\section{LEVEL OF PREPAREDNESS FOR PREVENTION AGAINST TERRORISM IN LIBRARIES: IMPLICATIONS FOR LIBRARIANS IN NIGERIA}

Roseline Echezona, Bredan Asogwa, Emmanuel Chigbue. University of Nigeria, NSUKKA

\subsection{6/injuryprev-2016-042156.804}

Introduction Terrorism is becoming a common occurrence in the world today. They came like robbers. In Africa and other developing countries of the world terrorism is prevalent. Most reports on terrorist attacks revealed that they strike when no one expected.

In Nigeria, terrorist activities which started in 2009 is still on. Boko Haram Islamic militants have unleashed devastating havoc on Nigerians through bombing of worshipping centres that if 